\title{
Satisfaction with Nursing Care among Cancer Patients Admitted In Oncology Wards at a National Referral Hospital in Kenya
}

Tabitha Karimi Ntarangwi"

Catherine Mwenda- School of Nursing, Mount Kenya University- Thika

Beatrice Nkoroi- School of Nursing, Mount Kenya University- Thika

\author{
DOI: $10.36348 /$ sjnhc.2019.v02i11.005 \\ | Received: 28.07.2019 | Accepted: 04.08.2019 | Published: 24.11 .2019 \\ *Corresponding author: Tabitha Karimi Ntarangwi
}

\section{Abstract}

Background: Nursing care is meeting both physical and psychosocial needs of patients. Cancer patients experience more biopsychosocial needs than other patients, hence they require more nursing care. An oncology nurse therefore provides physical, psychosocial and spiritual care to cancer patients. The purpose of this study was to assess satisfaction with nursing care among cancer patients admitted in oncology wards at Kenyatta National Hospital. Methodology: The study design was a descriptive cross-sectional, using both quantitative and qualitative approaches. The sample size was 91 patients who were selected using purposive sampling technique. The target population were adult patients (both males and females) aged 18 years and above admitted in oncology wards(GFD and 8C) at $\mathrm{KNH}$, with a confirmed diagnosis of cancer and who had received care for at least 48 hours. Data collection tool was a standardized researcher administered, semi structured questionnaire and Likert scale. Results: Majority of cancer patients, 53.8\% were not satisfied with psychosocial care with $97.8 \%$ (89) having their expectations on psychosocial care partially met. $97.8 \%$ (89) of the cancer patients identified emotional support as the priority psychosocial need, with $82.4 \%$ (75) recommending improvement of the same. Majority $(76.5 \%)$ had a neutral position with regard to satisfaction status with physical care. On general satisfaction, 94.5\% (88) were satisfied with care in the ward with $96.7 \%$ (84) reporting that physical care was most satisfying. Conclusion: Cancer patient satisfaction with nursing care had a positive association with their perceptions on nursing care offered in the ward. Psychosocial care was less satisfying to the cancer patients. Recommendation: Oncology nurses should be keen to meet all patient needs to promote care satisfaction with emphasis to psychosocial care.

Keywords: Satisfaction, nursing care, cancer patient, oncology nurse, oncology ward, physical care, psychosocial care.

Copyright @ 2019: This is an open-access article distributed under the terms of the Creative Commons Attribution license which permits unrestricted use, distribution, and reproduction in any medium for non-commercial use (NonCommercial, or CC-BY-NC) provided the original author and source are credited.

\section{INTRODUCTION}

Patient satisfaction by Schmidt et al. [1], is how patients' view the care provided to them based on their knowledge of ideal nursing care. According to Miller, [2], increased focus on patient centred care which entails considering patient views has made patient satisfaction to gain global interest as a key indicator of quality nursing care. Russel, [3] adds that in a health set up, nursing care is the major determinant of patient satisfaction. The nursing care needs to consider patient as an individual with specific needs and unique values. With this understanding, a nurse can offer care that is satisfying to the patient. Oncology Nursing is application of nursing assessment skills in offering oncology care to facilitate cancer patient's recovery or improvement in health, coping with physical and psychosocial problems, hence a better life, regardless of the stage of disease and accompanying effects until death [4].

The role of oncology nurses is to physically, emotionally, culturally and spiritually support the cancer patients and their families [5]. The recognition of cancer patient physical and psychosocial needs in a timely manner as been ranked as one of the best approach to promoting cancer patient quality care that leads to total patient satisfaction. This goes a long way to helping cancer patient cope with life and the effects of treatment [6]. Cancer patients who are newly diagnosed present with many physical and psychosocial needs which keep changing from time to time. This ends up affecting their overall functioning and wellbeing. Meeting these needs early enough promote cancer coping mechanism and enhance healing and selfimage [7]. 
Patient satisfaction is on close follow up globally, to help boost quality of care [8].Patient perceptions on nursing care should be given much considerations and nursing care accorded as per the patient views. The nurse needs to be aware of patient anticipations regarding their health needs and ensure that all of them are met [9]. This will enable a more sensitive and individualised care by the nurse leading to patient satisfaction.

Great effects of cancer on patient's life due to the treatment and the disease have brought the need to improve global care which entails taking into account various aspects of nursing care most importantly physical and psychosocial health [10]. According to Balogh et al. [11], global care of cancer patients has demonstrated unmet care needs. Most of these have to do with providing physical care and psychological attention to cancer patients. This points to the need of patient centered care that is timely and takes into account cancer patient priority needs and expectations.

In 2007, in a report on holistic cancer patient care by US institute of medicine showed that cancer care must consider physical and psychosocial needs. Flagg, [12], shares his sentiments that the approach to cancer patient care, needs to be holistic. Health care team needs to provide both physical and psychosocial needs as per patient's wishes and capabilities. According to Thorarinsdottir \& Kristjansson, [13], implementation of timely, holistic and sensitive nursing care to cancer patients increases patient satisfaction. However, despite the global scientific and technological advancement in cancer care, cancer patients remain with many problems that require comprehensive, sensitive and individualized nursing care [5].

According to WHO, globally 1 in 6 deaths is due to cancer, with more deaths being reported from less developed countries. Cancer comes third after infectious and cardiovascular causes of death in Kenya. The statistics approximate an incidence of 39,000 cases yearly and a mortality rate of greater than 27,000 deaths per year with cancer death rate set to double by 2026 (KDHS 2014- 2015) . Unmet Psychosocial and physical problems due to the disease and treatment have been found to contribute to high mortality rate among cancer patients than other patients. This supports the need for much nursing assistance required for cancer patients.

According to a study by La cava, Schwartz \& Asselin, [14], patients reported that nurses concentrated much of their energy in meeting their physical needs but unfortunately were unaware of their psychosocial needs. In other studies, nurses were found to give more emphasis on psychosocial care whereas patient valued the physical care. In oncology wards, studies indicate most cancer patient problems remain unmet because nurses do not often identify cancer patient needs and solve them [15]. Assessing cancer patient satisfaction on nursing care is therefore vital for a patient centred, prioritised care

\section{METHODOLOGY}

The study was conducted at Kenyatta National Hospital $(\mathrm{KNH}) . \mathrm{KNH}$ is the largest National referral and teaching hospital in Kenya and a regional referral Hospital in East Africa. It is located in Nairobi County off Mbagathi road. The hospital has 50 wards, 22 outpatient clinics, Accident and Emergency Department and 24 theatres (16 specialised). The bed capacity is 2000 with over 1700 nurses and 200 doctors. On average, bed occupancy is greater than $300 \%$. The study was conducted in the oncology wards; GFD and 8C each of which has a capacity of 32 patients, but number of patients at times may spill over to up to 60 .

This was a descriptive cross-sectional study. Both quantitative and qualitative approaches were used to assess satisfaction with nursing care among cancer patients admitted in oncology wards at Kenyatta National Hospital. The study population was adult cancer patients aged 18 years and above, admitted in the oncology wards at $\mathrm{KNH}$ for at least 48 hours with a confirmed diagnosis of cancer. A total of 91 cancer patients were sampled using purposive sampling technique. A semi-structured, researcher administered questionnaire and Likert scale in both English and Kiswahili version was used to collect data. The tool was pretested with nine ( $10 \%$ of sample size) cancer patients admitted in Nakuru County Hospital which is also a referral hospital for the county and admits a large number of cancer patients. The tool was then amended accordingly to ensure validity and reliability. The cronbach's alpha co-efficient was 0.819 which meant a high degree of internal consistency.

After seeking permission from the ward in charges, the researcher used the nurses working in the respective wards to assist in identifying the potential cancer patients that met the above criteria. The researcher and the research assistants also reviewed the patient's files twice a week to identify those patients who met the inclusion criteria. Data analysis was done using SPSS version 21.The quantitative data was analysed using descriptive statistics. The qualitative analysis involved identifying themes and patterns and then organizing into categories based on the themes. Inferential statistics (chi-square test and odds ratio) was used to find the association between independent and dependent variable. Regression analysis was done for the various variables influencing level of satisfaction (based on chi-square results) using forward selection method to eliminate confounding variables.

The researcher got ethical clearance from MKU/ERC, Ref. No. MKU/ERC/0855, NACOSTI research Permit No: NACOSTI/P/18/61097/23284, Approval from KNH-UoN ERC (P531/07/2018), and a Study Registration Certificate endorsed by $\mathrm{KNH}$ head 
of Oncology Department. Ward in charge was asked for permission to access the participants. Respect for individual participants was expressed by recognising their autonomy and right to self-determination.
Confidentiality and anonymity was assured to the participants. The nature and purpose of the research was explained to participants to enable them give consent.

\section{RESULTS}

Table-1: Socio-Demographic Characteristics (Gender, Age, Religion, Marital Status)

\begin{tabular}{|l|c|c|}
\hline Characteristic & Frequency(n) & Percentage (\%) \\
\hline Gender & 49 & 53.8 \\
Male & 42 & 46.2 \\
Female & $\mathbf{9 1}$ & $\mathbf{1 0 0}$ \\
Total & & \\
\hline Age in years & 15 & 16.5 \\
18-29 & 15 & 16.5 \\
30-39 & 16 & 17.6 \\
40-49 & 27 & 29.7 \\
50-59 & 18 & 19.8 \\
$>60$ & $\mathbf{9 1}$ & $\mathbf{1 0 0}$ \\
Total & & \\
\hline Religion & 90 & 98.9 \\
Christian & 1 & 1.1 \\
Muslim & $\mathbf{9 1}$ & $\mathbf{1 0 0}$ \\
Total & & \\
\hline Marital status & 19 & 20.9 \\
Single & 64 & 70.3 \\
Married & 5 & 5.5 \\
Separated & 3 & 3.3 \\
Widowed & $\mathbf{9 1}$ & $\mathbf{1 0 0}$ \\
Total & & \\
\hline
\end{tabular}

Table 1 above shows that $53.8 \%$ (49) were males while $46.2 \%$ (42) were females. The ages of the respondents were evenly distributed with $16.5 \%$ (15) aged between $18-29,16.5 \%$ (15) between $30-39,17.6 \%$ (16) between 40-49, 29.7\% (27) between 50-59 and
$19.8 \%$ (18) aged above 60 years. Majority were Christians with $98.9 \%$ (90) while $1.1 \%$ (1) were Muslims. Most of the respondents were married with $70.3 \%$ (64), $20.9 \%$ (19) were single, $5.5 \%$ (5) were separate and $3.3 \%$ (3) were widowed.

Table-2: Expectations on Nursing Care Offered In the Ward

\begin{tabular}{|l|l|l|l|l|l|}
\hline $\begin{array}{l}\text { Patient's expectation of the } \\
\text { nursing care }\end{array}$ & S.D & D & N & A & S.A \\
\hline To be friendly & 0 & 0 & $\begin{array}{l}1.1 \% \\
(1)\end{array}$ & $\begin{array}{l}\text { 97.8\% } \\
(89)\end{array}$ & $\begin{array}{l}1.1 \% \\
(1)\end{array}$ \\
\hline To be empathetic & 0 & 0 & $\begin{array}{l}2.2 \% \\
(2)\end{array}$ & $\begin{array}{l}96.7 \% \\
(88)\end{array}$ & $\begin{array}{l}1.1 \% \\
(1)\end{array}$ \\
\hline To be compassionate & 0 & 0 & $\begin{array}{l}2.2 \% \\
(2)\end{array}$ & $\begin{array}{l}95.6 \% \\
(87)\end{array}$ & $\begin{array}{l}2.2 \% \\
(2)\end{array}$ \\
\hline To be sensitive & 0 & 0 & $\begin{array}{l}2.2 \% \\
(2)\end{array}$ & $\begin{array}{l}95.6 \% \\
(87)\end{array}$ & $\begin{array}{l}2.2 \% \\
(2)\end{array}$ \\
\hline To meet my physical needs & 0 & 0 & $\begin{array}{l}1.1 \% \\
(1)\end{array}$ & $\begin{array}{l}97.8 \% \\
(89)\end{array}$ & $\begin{array}{l}1.1 \% \\
(1)\end{array}$ \\
\hline To meet my psychosocial needs & 0 & 0 & $\begin{array}{l}2.2 \% \\
(2)\end{array}$ & $\begin{array}{l}96.7 \% \\
(88)\end{array}$ & $\begin{array}{l}1.1 \% \\
(1)\end{array}$ \\
\hline To treat me as an individual & 0 & 0 & $\begin{array}{l}2.2 \% \\
(2)\end{array}$ & $\begin{array}{l}95.6 \% \\
(87)\end{array}$ & $\begin{array}{l}2.2 \% \\
(2)\end{array}$ \\
\hline To respect my beliefs and values & 0 & 0 & $\begin{array}{l}2.2 \% \\
(2)\end{array}$ & $\begin{array}{l}96.7 \% \\
(88)\end{array}$ & $\begin{array}{l}1.1 \% \\
(1)\end{array}$ \\
\hline $\begin{array}{l}\text { To inform me and my family } \\
\text { about the disease, treatment and } \\
\text { the side effects }\end{array}$ & 0 & $\begin{array}{l}1.1 \% \\
(1)\end{array}$ & $\begin{array}{l}1.1 \% \\
(1)\end{array}$ & $\begin{array}{l}96.7 \% \\
(88)\end{array}$ & $\begin{array}{l}1.1 \% \\
(1)\end{array}$ \\
\hline $\begin{array}{l}\text { To involve frequent checking of } \\
\text { my progress }\end{array}$ & 0 & 0 & $\begin{array}{l}1.1 \% \\
(1)\end{array}$ & $\begin{array}{l}94.5 \% \\
(86)\end{array}$ & $\begin{array}{l}4.4 \% \\
(4)\end{array}$ \\
\hline
\end{tabular}

Key: S.D-Strongly disagree, D-Disagree, N-Neutral, A-Agree, S.A-Strongly agree 
Table 2 above shows that most responses were "agree" which had $96.4 \%$ (877) of the total responses, "strongly agree" had 1.8\% (16), "neutral" had $1.8 \%$ (16), "disagree" had $0.1 \%$ (1) and "strongly disagree" had $0 \%$. This indicated that the respondents had generally high expectations on nursing care offered in the ward.

Table-3: Satisfaction with Psychosocial Care

\begin{tabular}{|l|l|l|l|}
\hline Psychosocial care & $\mathbf{N S}$ & $\mathbf{N}$ & $\mathbf{S}$ \\
\hline Nurse is available when I need him/her & $7.7 \%$ & $31.9 \%$ & $60.4 \%$ \\
\hline $\begin{array}{l}\text { Nurse encourages me to verbalize fears and } \\
\text { concerns }\end{array}$ & $5.5 \%$ & $39.6 \%$ & $54.9 \%$ \\
\hline $\begin{array}{l}\text { Nurse educates me and my family on cancer disease } \\
\text { e.g. cause, treatment, prevention }\end{array}$ & $73.6 \%$ & $24.2 \%$ & $2.2 \%$ \\
\hline $\begin{array}{l}\text { Nurse educates me on coping strategies e.g. joining } \\
\text { cancer support groups, involving family members, } \\
\text { and getting a medical insurance cover }\end{array}$ & $69.2 \%$ & $28.6 \%$ & $2.2 \%$ \\
\hline Nurse respects my privacy & $8.8 \%$ & $83.5 \%$ & $7.7 \%$ \\
\hline Nurse involves spiritual adviser as I desire & $72.5 \%$ & $24.2 \%$ & $3.3 \%$ \\
\hline Nurse organizes counselling for me and my family & $74.7 \%$ & $22 \%$ & $3.3 \%$ \\
\hline $\begin{array}{l}\text { Nurse emotionally supports me on anticipatory } \\
\text { grieving, altered appearance, altered sexual } \\
\text { function, hair loss and changes in family role }\end{array}$ & $70.3 \%$ & $24.2 \%$ & $5.5 \%$ \\
\hline Nurse addresses my employment needs & $78 \%$ & $17.6 \%$ & $4.4 \%$ \\
\hline Nurse addresses my financial needs & $78 \%$ & $16.5 \%$ & $5.5 \%$ \\
\hline Average satisfaction level & $53.8 \%$ & $31.2 \%$ & $14.9 \%$ \\
\hline
\end{tabular}

Key: NS=Not satisfied, N-Neutral, S-Satisfied

Table 3 above shows that most responses i.e.53.8\% (490) was for "not satisfied", $31.2 \%$ (284) were for "neutral" and 14.9\% (136) were for satisfied.

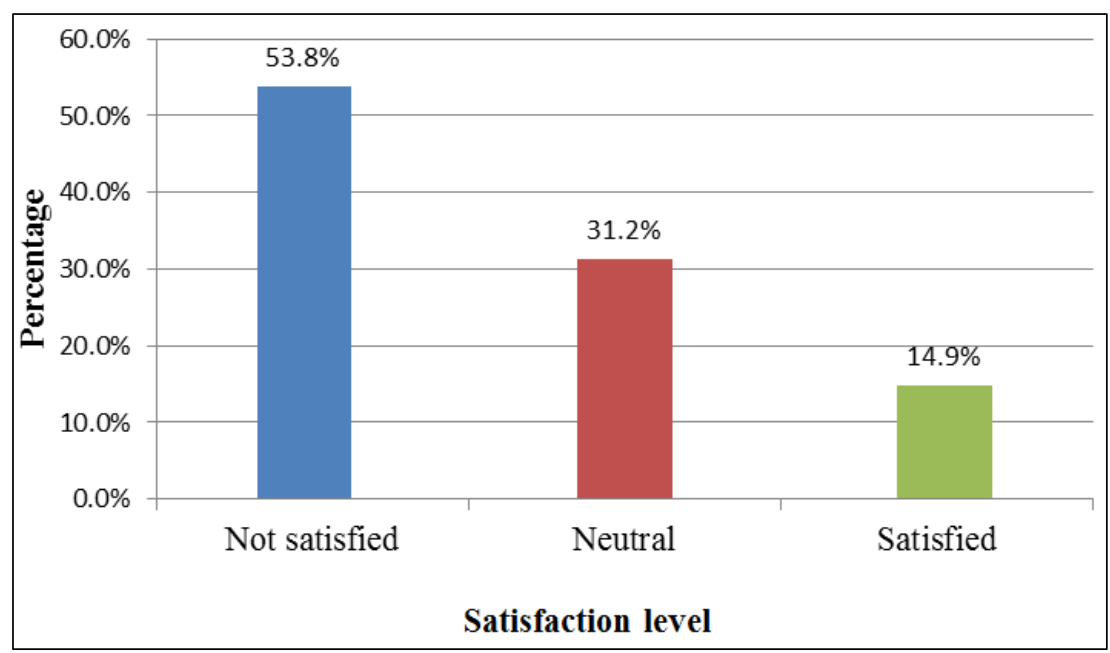

Fig-1: Satisfaction Status for Psychosocial Care Offered in the Ward

The patients' priority needs were analyzed whereby the researcher picked the number one need on the list. Majority i.e.97.8\% (89) had emotional support as the priority need while $2.2 \%$ (2) had no priority psychosocial need. On whether expectations for psychosocial care had been met, 97.8\% (89) reported that the expectations were partially met while $2.2 \%$ (2) said the expectations were fully met.
Respondents gave several recommendations on improvement of psychosocial care whereby $48.4 \%$ (44) recommended patient and family education, $82.4 \%$ (75) recommended improvement of emotional support, $15.4 \%$ (14) recommended frequent assessment of patient's needs, $2.2 \%$ (2) recommended that nurse be available as needed and $2.2 \%$ (2) recommended improvement of NHIF efficiency. 


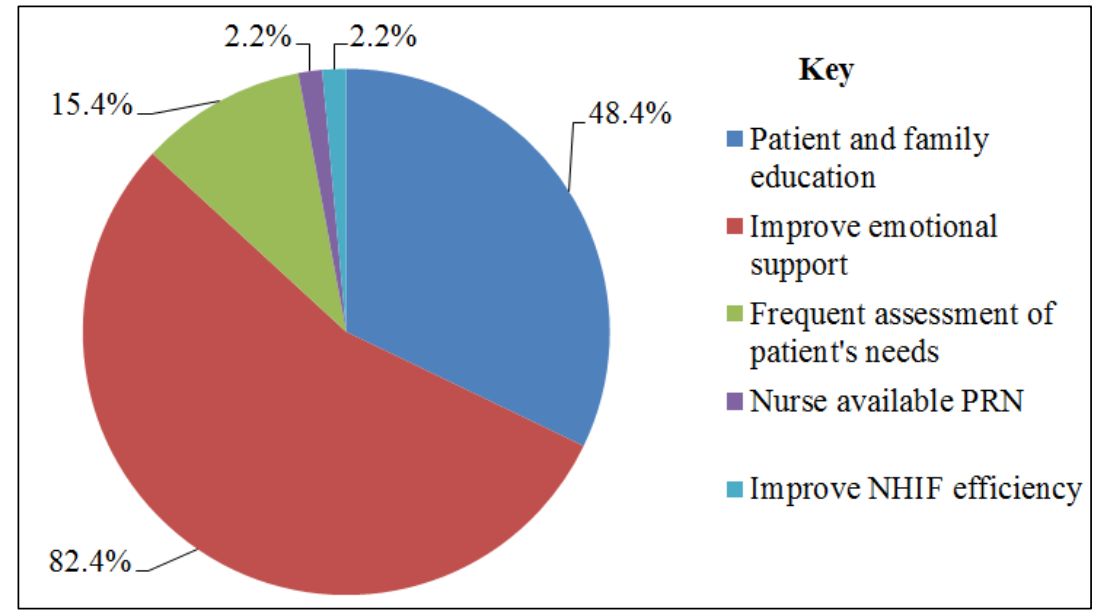

Fig-2: Recommendations for improvement of psychosocial care

Table-4: Satisfaction with physical nursing care

\begin{tabular}{|l|l|l|l|}
\hline Physical care item & $\mathbf{N S}$ & $\mathbf{N}$ & $\mathbf{S}$ \\
\hline Nurse checks my vital signs every 4 hours & $82.4 \%$ & $15.4 \%$ & $2.2 \%$ \\
\hline Nurse cleans the wound daily and when need be & $7.7 \%$ & $91.2 \%$ & $1.1 \%$ \\
\hline Nurse assesses oral cavity \& provides care daily & $17.6 \%$ & $80.2 \%$ & $2.2 \%$ \\
\hline $\begin{array}{l}\text { Nurse asks me for signs of nausea and vomiting } \\
\text { and gives me antiemetic as need be }\end{array}$ & $11 \%$ & $81.3 \%$ & $7.7 \%$ \\
\hline Nurse keeps away unpleasant sights and odours & $9.9 \%$ & $86.8 \%$ & $3.3 \%$ \\
\hline Nurse ensures I have enough rest & $4.4 \%$ & $91.2 \%$ & $4.4 \%$ \\
\hline $\begin{array}{l}\text { Nurse encourages me to take small frequent, high } \\
\text { calorie and high protein meals }\end{array}$ & $9.9 \%$ & $85.7 \%$ & $4.4 \%$ \\
\hline $\begin{array}{l}\text { Nurse assesses my pain and discomfort frequently } \\
\text { and gives me pain medications as need be }\end{array}$ & $9.9 \%$ & $70.3 \%$ & $19.8 \%$ \\
\hline $\begin{array}{l}\text { Nurse teaches me on non-pharmacological pain } \\
\text { relief methods e.g. distraction ,imagery and } \\
\text { relaxation }\end{array}$ & $11 \%$ & $85.7 \%$ & $3.3 \%$ \\
\hline $\begin{array}{l}\text { Nurse assists me with daily activities such as bed } \\
\text { making, hygiene, grooming, elimination and } \\
\text { ambulation }\end{array}$ & $4.4 \%$ & $76.9 \%$ & $18.7 \%$ \\
\hline \begin{tabular}{l} 
Average satisfaction level \\
\hline
\end{tabular} & $16.8 \%$ & $76.5 \%$ & $6.7 \%$ \\
\hline
\end{tabular}

Key: NS-Not satisfied, N-Neutral, S-Satisfied

Table 4 above shows that, majority of the responses i.e.76.5\% (696) indicated a neutral position with regard to satisfaction status, $16.8 \%$ (153) indicated "not satisfied" and 6.7\% (61) indicated satisfaction with physical care. Majority of the respondents i.e. $96.7 \%$ (88) felt that their expectation on physical care had been partially met, $2.2 \%$ (2) felt they had been fully met, while $1.1 \%$ (1) felt the physical care expectations had not been met.

Respondents had recommendations for improvement of physical care whereby $52.7 \%$ (48) recommended assessment of patient's needs, 4.4\% (4) recommended medication administration monitoring, $24.2 \%$ (22) recommended prompt intervention with respect to drug administration and blood transfusion, $6.6 \%$ (6) recommended nurse availability when needed, $4.4 \%$ (4) recommended nurse to be more sensitive to physical needs/monitoring of patients' progress, $2.2 \%$ (2) avail chemotherapy drugs and $1.1 \%$ (1) recommended food improvement/monitoring of drug side effects/inform patient of his progress/avail hospital uniform/provision of holistic care.

\section{DISCUSSION}

Majority $(53.8 \%)$ of the patients were not satisfied with psychosocial care offered in the ward. This compares with other studies done to include a study by Alaca et al. [16], whereby cancer patients expressed that nurses devoted most of their time meeting their physical needs unaware of the psychosocial needs they had and which they perceived to be more important. Similarly in a study done in oncology ward in Australia by Marven, [17], cancer patients expressed that the psychological care was the first to be missed by nurses. This may have been attributed to the fact that psychosocial care was left to social worker and pastoral team. Still in another study done in oncology wards in Australia and Victoria talking to patients was rated the most common missed care $(88.2 \%)$, followed by failure to update care plans(76.5\%), and educating patient and family 
(64.7\%). This study showed that cancer patients were most dissatisfied with psychosocial care.

In this current study, the main priority psychosocial need was emotional support which was mentioned by $97.8 \%$. This agrees with a study by Mahendran et al. [10], in Singapore which highlights emotional concerns as a priority psychosocial need of a cancer patient. Smeltzer et al. [5] also agrees that psychological distress will always accompany a cancer diagnosis even if it has good prognosis and requires no radical therapy. The fact that one is diagnosed with cancer therefore has enormous effect on psychosocial well-being [18]. Still the Lance Armstrong Foundation of cancer survivors in their report in 2010[22], 45\% of the patients reported their emotional needs were unmet, $46 \%$ lacked grieving care, while $39 \%$ missed attention for the low mood. These unmet needs at the end of it reflected on incomplete psychosocial care.

Majority of cancer patients, $97.8 \%$ felt that their expectations on psychosocial care were partially met. This agrees with a study by Daniel, [9], where cancer patient were found to expect all their needs to be met by the nurse, but in most cases their psychosocial needs were partially met. On recommendations for psychosocial care, majority $(82.4 \%)$ recommended improvement of emotional support. This agrees with a study by Rejab, [19] which indicated that a positive caring attitude towards patient promotes patient satisfaction with care. Similarly according to Alashek, [20], nurses provide the main connections with patients by acting as patient advocate, and provide both physical care and emotional support to patient and family. This in the long run promotes patient satisfaction with care affecting their overall perception on care.

On satisfaction with physical care, majority of respondents $(76.5 \%)$ held a neutral position. These cancer patients felt that nurses were different in that there those who provided physical care satisfactorily whereas others did not hence making the participants take a neutral position. They also expressed that most nurses are females hence sometimes experience mood changes affecting the quality of care.

The priority physical need was treatment, which was mentioned by $37.4 \%$ and pain management mentioned by $26.4 \%$. In contrast, according to Smeltzer et al. [5], pain is ranked as the priority physical need for a cancer patient. Majority (96.7\%) felt their expectations on physical care were partially met. This contrasts with a study by Alaca et al. [16] where cancer patients expressed that nurses devoted most of their time meeting their physical needs unaware of the psychosocial needs which they perceived to be more important. Similarly, a study by Eman et al. [21], pointed out that nurses emphasized more on psychosocial care while patient valued the physical care more.
Most of them (52.7\%) recommended that nurses improve on need assessment. This agrees with a study by Thorsen et al. [15] which noted that a prioritized, comprehensive nursing care is lacking in most oncology wards. The same study noted that cancer patients have more physical and psychosocial unmet needs compared to other patients.

Majority $(59.3 \%)$ felt that both physical and psychosocial care was equally important. This agrees with a 2007 report on holistic cancer care which showed that cancer care must embrace the physical and psychosocial care. Solving the physical effects of a cancer patient therefore is as equally important as solving their psychosocial needs. On general level of satisfaction, $94.5 \%$ were satisfied with care in the ward out of whom $97.6 \%$ found physical care most satisfying. This is similar to a study by Alaca et al. [16], where cancer patients expressed that they were most satisfied with physical care.

\section{CONCLUSION}

Cancer patients had generally high expectations on nursing care offered in the ward. The level of satisfaction with psychosocial care and physical care significantly affected perception on nursing care offered in the ward. Most cancer patients were not satisfied with psychosocial care because their psychosocial needs were not met. The priority psychosocial need was emotional support.Cancer patients maintained a neutral position regarding level of satisfaction with physical care. Physical needs were partially met with provision of treatment being the priority physical need, followed by pain. Cancer patients were generally satisfied with nursing care offered in the ward with physical care being most satisfying.

\section{RECOMMENDATIONS}

- Nurses should aim at meeting patient expectations by assessing their needs frequently to ensure that their needs are met which leads to satisfaction with care given. Nurses should also be aware that cancer patients have high expectations with nursing care (both psychosocial care and physical care) hence work at meeting these needs.

- There is a great need for oncology nurses to implement psychosocial care with the same emphasis as physical care. This will call for the nurse to interact closely with patient to identify psychosocial needs and be able to meet them adequately. Emotional support to cancer patients needs to be emphasized.

- Nursing training institutions needs to emphasize psychosocial care in cancer patient plans of care.

- Oncology nurses need also to improve the physical care by periodic assessment of patient needs and working at meeting them fully and timely. 
- Treatment for cancer patient when admitted in the ward needs to be availed on time and monitored closely.

- Policy makers on cancer care should emphasize psychosocial care and timely, subsidized, affordable cancer treatment.

- There is need to further investigate the challenges that nurses may be facing in delivery of psychosocial care to cancer patients. This is because according to this study, most cancer patients were not satisfied with psychosocial nursing care offered to them while admitted in the ward. Further research also needs to focus on a model that can be used by nurses to boost quality psychosocial nursing care to cancer patients admitted in the oncology wards.

\section{REFERENCES}

1. Greenman, C., Stephens, P., Smith, R., Dalgliesh, G. L., Hunter, C., Bignell, G., ... \& Edkins, S. (2007). Patterns of somatic mutation in human cancer genomes. Nature, 446(7132), 153.

2. Miller, W. R., \& Rollnick, S. (2012). Motivational interviewing: Helping people change. Guilford press.

3. Russell, K. (2014). The perceptions of burnout, its prevention and its effect on patient care as described by oncology nurses in the hospital setting (Doctoral dissertation, Carlow University).

4. Taylor, C., Lillis, C., LeMone, P., \& Lynn, P. A. (2001). Fundamentals of nursing: The art and science of nursing care(pp. 530-40). Philadelphia: Lippincott.

5. Smeltzer, S. C., \& Bare, B. G. (2013). Brunnerand Suddarths Textbook of Medical. Surgical Nursing..

6. Jacobsen P.B. (2017). A Health care delivery, dissemination and implementation research model to promote Psychosocial care in routine cancer care. Psycho-oncology, 27(16), 419-423.

7. Ghoshal, S., Miriyala, R., Elangovan, A., \& Rai, B. (2016). Why newly diagnosed cancer patients require supportive care? An audit from a regional cancer center in India. Indian journal of palliative care, 22(3), 326.

8. Senarath, N.S., Gunawardena, B.S., Arosha, S., Sachintha, L., Ahushka, S., Madushan, J., \& Dilshan, W. (2013). Patient satisfaction with nursing care and related Hospital services at the National Hospital of Sri Lanka. Leadership in health services, 26(1), 63-67

9. Daniel, L. (2012). The relationship between nurse staffing and patient satisfaction in an Emergent Department (Doctoral Dissertation University of Toronto)
10. Mahendran R. Lim A. Chua J., Kua H., Waun E. (2017). Psychosocial concerns of cancer patients. Asia-Pac J. Clin Oncol, 1(3), 96-103.

11. Balogh, E.P., Ganz, P.A., Murphy, S.B., Nass, S.J, Ferall, B.R., \& Stovall, E. (2011). Patient centered cancer treatment planning: Improving the quality of oncology care. The Oncologist, 16 (12), 1800-1805,

12. Flagg, A.J., (2015). The Role of Patient centered care in Nursing. Nursing clinics of North America $50(1)$

13. Thorarinsdottir, K. \& Kristjansson, K. (2013). Patient perspectives on patient-centred participation in health care. Nursing ethics, 18(3), 400-416.

14. Osterman, P. L. C., Schwartz-Barcott, D., \& Asselin, M. E. (2010, July). An exploratory study of nurses' presence in daily care on an oncology unit. In Nursing Forum (Vol. 45, No. 3, pp. 197205). Malden, USA: Blackwell Publishing Inc.

15. Thorsen, L., Gjerset, G. M., Loge, J. H., Kiserud, C. E., Skovlund, E., Fløtten, T., \& Fosså, S. D. (2011). Cancer patients' needs for rehabilitation services. Acta Oncologica, 50(2), 212-222.

16. Alaca, Ç., Yiğit, R., \& Özcan, A. (2011). Comparison of nurses' and patients' opinions about their experiences during the disease process of inpatients in the intensive care unit. Journal of Psychiatric Nursing, 2(2), 69-74.

17. Marven, A. C. (2016). Missed nursing care-a nurse's perspective: an exploratory study into the who, what and why of missed care.

18. KALAY, H. A. TÜRK EL SANATLARININ YARATICI TURIZM BAĞLAMINDA KULLANILABİLIRLİĞİ ÜZERINE BIR ARAŞTIRMA. NEW TRENDS IN SOCIAL AND LIBERAL SCIENCES-2, 373.

19. Rejab, I. B. (2013). A Conceptual Framework of the Relationship Between Service Quality and Patient Satisfaction In Public and Private Hospitals in Tripoli, Libya: The Importance of Hospital Access And Cost. Al-Madinah Managment and Finance Science, 3(1).

20. Alashek, W. A., McIntyre, C. W., \& Taal, M. W. (2011). Provision and quality of dialysis services in L ibya. Hemodialysis International, 15(4), 444452.

21. Eman, M.A., Aide, E.G., Nagwa, M.A., \& Ahmed, A.S. (2013. Oncology Nurses versus oncology patient perception of caring behaviours given to patients in oncology units. Medicine Journal Cairo University, 8(2), 11-20.

22. Rechis, R., Reynolds, K. A., Beckjord, E. B., Nutt, S., Burns, R. M., \& Schaefer, J. S. (2011). I learned to live with it" is not good enough: Challenges reported by post-treatment cancer survivors in the LIVESTRONG surveys. Austin, TX: LIVESTRONG. 